\title{
Equity - some theory and its policy implications
}

Anthony J Culyer University of York

\begin{abstract}
This essay seeks to characterise the essential features of an equitable health care system in terms of the classical Aristotelian concepts of horizontal and vertical equity, the common (but ill-defined) language of "need" and the economic notion of cost-effectiveness as a prelude to identifying some of the more important issues of value that policy-makers will have to decide for themselves; the characteristics of health (and what determines it) that can cause policy to be ineffective (or have undesired consequences); the information base that is required to support a policy directed at securing greater equity, and the kinds of research (theoretical and empirical) that are needed to underpin such a policy.
\end{abstract}

Keywords: Health care systems; equity; horizontal equity; vertical equity; cost-effectiveness

Theoretical discussions of equity are often distanced from the practical world of policy. In this essay, an attempt is made to bridge the gap. Equity in health care policy, as in other arenas of policy, is a question of ethics and therefore of values. I am not concerned here with descriptive ethics (which depicts the values people seem to hold but which is a research area that is too neglected) but with analytical ethics (which asks what we ought to do). The focus is on equity in the allocation of health care resources. I am therefore concerned with questions like: "what is an equitable distribution of the available health care resources among residents of a country?"; "is the present distribution of health care resources in my country equitable?", and "how might the distribution be made more equitable?" These are value-laden questions because any idea of "equity" must embody value judgments about what it is that makes for a good society. At the same time, the questions generate empirical questions of fact if they are to have policy-relevance. We are likely to want to know what the present distribution of resources is and we may even want to know, as a matter of fact, what it is that ordinary people think about that distribution. There are, of course, values underlying the reason for asking such factual questions and many of them relate to equity. But the questions themselves are not ones of value. To determine whether they have been satisfactorily answered requires judgments that are not valuejudgments, for example, whether the number of hospital beds counted in England and Wales is accurate or whether the population sampled was representative of the groups whose opinions were sought.

The aim is not to provide a set of definitive answers to questions of value. Rather, it is to lay out some issues that need resolution and explore how such questions are best answered in the context of a modern, affluent, and industrialised society in which government bears much of the responsibility both for the global resources available for health services and for their distribution. The goal, then, is to help clarify the central issues. Although no one has a monopoly on moral authority in this terrain, public policy development can best proceed if there is broad agreement on a set of guiding principles or policy assumptions.

\section{A pluralist approach for a pluralist society}

There is disagreement about the meaning of equity among and between the general public, philosophers, political theorists and economists. All include the word in their vocabularies. There are some who deny that it has any relevance to public policy whatsoever and others, even more extreme, who deny that it has any useful meaning at all. The first task, therefore, is that of definition, enabling the reader to form a judgment about the significance of equity in public policy toward health and health care.

Plainly there is no single, universal theory of equity, but it is widely agreed that equity implies equality. Unfortunately, there is no accord concerning what should be equal. The absence of an agreed theory arises out of the absence of a general or monist theory of morality. There are moral theories that claim to be general, such as utilitarianism, though utilitarianism in its classical form was not directly concerned with equity. But each theory has to contend with other, often attractive, theories. Non-utilitarian theories hold, variously, that the equitable distribution of health care resources is that which is to the advantage of the least advantaged person-so-called maximin theory; that equitable distribution arises out of the duty of each of us (perhaps by divine fiat) to provide for others-deontological theory; or that equitable distribution is the outcome of an equitable economic and social system-entitlement theory (for a review of these see Veatch). ${ }^{1}$ Each of these theories generates several principles and rules which conflict with those of the others. 
It therefore seems inevitable that equity issues are best considered as pluralist. ${ }^{2}$ We must weigh and balance rival concepts, rival theories and rival disciplines, rejecting any completely only where there is contradiction and only one principle can survive, through assessing the force of each and according it a weight commensurate with the degree to which it is ethically compelling. The purpose of this approach is to narrow the range of possibilities and to determine the significance of the different elements.

\section{Why is health care important?}

Why be concerned about equity in health care distribution? Part of the answer is that health care serves a significant end-individuals' healthalthough health care is not the only means to serve this end. Moreover, health services serve other ends: providing information, reassurance, counselling, certification, legitimisation of sickness states for those seeking insurance benefits, and a variety of other services marginally connected with health. It is, however, the link between health care and health that is important in equity because health is important in ways that the other needs served by health care are not.

What is this particular significance about health that raises its status in equity above other services? The answer seems to be that health, like the cognitive skills developed by educational institutions, is one of a special set of characteristics (sometimes called "primary goods") about whose distribution people are particularly concerned. Tobin ${ }^{3}$ uses the term "specific egalitarianism" because health care services are regarded as fundamentally necessary to the good life. Aristotle termed this concept "eudaemonia", which is usually taken to mean "flourishing" . This is not the same as the naive utilitarian notion of "satisfaction", whose limitations are well highlighted by John Stuart Mill's famous remark: "Better to be a human being dissatisfied than a pig satisfied" (though it may also be better to be a human being dissatisfied than a flourishing pig). In a very basic sense, one cannot "flourish" at all if one is dead or diseased. Care that postpones death, diminishes disease, or eliminates destructive influences on the quality of living, improves the capacity for savouring all that life has to offer, and not merely its pleasures. Entities such as health derive equity significance from their ability to enable people to "flourish". Health and sickness are also culturally contingent: the things and attributes you need to flourish in Britain today may not be the same as those you needed in the middle ages, nor are they necessarily the same as are needed now in Bangladesh.

If it is felt that all residents of a political jurisdiction ought to have equal opportunities for their lives to flourish, then it follows that health care is one of the goods and services whose right distribution must be ensured. Precision in the meaning of flourishing is less critical than agreement that the concept captures diverse but fundamental aspirations that are dependent on better health.
The idea of fundamental requirements-that bread is more basic than jam or that needs trump desires-has received some attention in the economics literature. For example, $\mathrm{Sen}^{5-7}$ criticises conventional welfare economics for attaching social value only (a) to goods and services and (b) to the utility they afford consumers and externally affected parties. Economics ought also to attach value to the capabilities (such as the ability to flourish) that exist and that can be developed in people.

\section{What is equity? An economist's view}

In essence all equity approaches judge the treatment of individuals inequitable if it is capricious or relates to "irrelevant" characteristics. Commonly cited characteristics of this sort include race, religion, and gender. These may sometimes become relevant-for example, dietary restrictions and other prohibitions of some religions are regarded as legitimate grounds for patients to be treated differently. Equality and equity, and inequality and inequity, are not the same, although they are intimately related. Equity in health care requires that patients who are alike in relevant respects be treated in like fashion and that patients who are unlike in relevant respects be treated in appropriately unlike fashion. These requirements correspond to a familiar distinction between horizontal and vertical equity.

Horizontal equity requires the like treatment of like individuals and vertical equity requires the unlike treatment of unlike individuals, in proportion to the differences between them. Some of the ways in which people are generally considered like or unlike-such as "health" or "need"-are taken up later. But supposing that "need" is selected as the only relevant factor, then the two principles would imply that like needs should receive like attention and resources (horizontal equity) and that greater needs should receive greater attention and resources (vertical equity). Horizontal and vertical equity considerations apply also to entities other than health. One closely related entity is the financial contribution to health care. A horizontal principle here might be, "equal contributions from households having an equal ability to pay" and the corresponding vertical principle would, of course, be "higher contributions from households with a higher ability to pay". Such principles clearly separate payment for medical care from the willingness of households to pay for it. In considering need, these principles also separate receipt of care from willingness (as conditioned by ability) to pay. And the same implications would pertain even if "need" were not adopted as the distributional principle-so long as whatever replaced need did not correlate with ability/willingness to pay.

There is a prevalent view in the wealthy world that policy ought to concern itself only with the distribution and redistribution of income (and wealth), leaving it up to individuals to determine their preferred consumption of goods and services, including health care, by appropriate purchases, 
taking into account such taxes and transfers necessary to satisfy the requirements of vertical equity. There are, however, two difficulties with an equity focus on purchasing power alone. One is that people care more about the fairness of the distribution of "important" commodities like health care than they do about other purchasable items, ${ }^{3}$ so that even an equalisation of incomes may leave substantial inequities in the "important" entities. The other is the difficulty of identifying the principles that ought to guide income distribution independently of what it is that people can buy with their incomes and the moral significance of their purchases. For example, if it is said that health care ought to be allocated in proportion to need, then the income redistribution must account for the different needs of, say, those with ischaemic heart disease, those needing continuous nursing, those chronically disabled, and the costs of services required. These needs and the cost of meeting them must then become part of the criteria for appropriate income redistribution. If income distribution policy is developed independently of the specific concerns that inequity raises, what is its ethical justification? On the other hand, if there are specific distributive concerns, why not focus policy specifically on them?

Assuming there is a concern for horizontal and vertical equity in health care, it is clear that the concept of equity hangs on the meanings attached to words like "relevant", "treated", and "appropriately". Before taking up these issues, there is another preparatory issue to be resolved concerning the level of equity to address through public policy: should it be the individual level, for example, doctor-patient, or a more collective level, for example, interregional, interclass, or interinstitutional?

\section{Macro and micro equity}

Although equity and inequity may be usefully discussed in terms of the differences between individuals, a distinction needs to be made between individuals, that is, named persons, and representative individuals, such as the "typical resident of Bangladesh", a "typical patient with ischaemic heart disease" or a "patient on a waiting list". It is important, if equity is significant, for equity to apply at the individual, or micro level of the doctorpatient relationship, or at the interface between the patient and the hospital. For example, it is a common tenet of medical ethics that doctors ought to have equal respect for individuals' autonomy in all dealings with patients. ${ }^{8}$ There are also doubtless more and less equitable ways of scheduling patients on waiting lists for admission to elective surgery.

The focus here is, however, on macro equity and particularly on the equity of the distribution of health care across categories of persons deemed relevant: for example, the geographic distribution of resources, across categories of persons, the utilisation of services by those in equal need across different socioeconomic groups, or the contribution made to equity by various medical specialties. Macro equity is concerned with programmes rather than with patients and with the decisions leading to the distribution of resources among client groups. At the micro level, it is the doctor's obligation to use the available resources in ways deemed best for patients within the requirements of medical ethics. It is clear, however, that medical ethics, traditionally devised for micro purposes, is inadequate to determine the equitable distribution of resources between programmes, specialties, hospitals, or other health care delivery agencies. One doctor may be a good judge of the needs of his or her own patients, but doctors will rarely be in an objective position to weigh either the rival claims of other physicians who make demands on behalf of their patients, or the strength of their own claims vis-a-vis others. For such macro programmatic decisions, judgments of a broader kind are required.

\section{What is 'relevant' 'appropriate' 'treatment'?}

Two problems arise in interpreting "treatment". First, not all health care is intended to serve health. For example, it is possible to conceive of the hotel services of hospitals being offered at different quality levels, without this having much impact on the effectiveness of medical care. The range may be from one star to five, with private and semi-private rooms or ward-based care, different quality food menus, and so on. Thus, if equity of distribution derives from the ethical importance attached to health, then not all health-affecting care services have equal equity significance and may be irrelevant. One might, for example, envisage a system in which individual choice and the power of the purse (usually via insurance arrangements) determined the level of hotel services with equity focused on the distribution specifically of health-affecting care. Second, not all health care intended to be effective is actually effective. Even among effective treatments, moreover, there is usually choice. For example, medicine may sometimes be substituted for surgery (or vice versa), nursing care for physician care, inpatient for outpatient, prevention for cure, and so on. Moreover, some treatments that are effective may not be cost-effective. Such treatments are also irrelevant in equity.

On efficiency grounds, care which is not cost-effective ought to be eliminated. Health care that is not related to the protection, promotion, and restoration of health may have ample justification in terms of the satisfaction of consumer preferences, but it is not to be evaluated by equity criteria.

\section{Is merit 'relevant'?}

Several writers (for example Mooney') have enumerated characteristics of individuals relevant to equity judgments. According to one argument, a relevant characteristic is the "merit" of individuals based on judgments about their contribution to society. Here further judgments might be involvedfor example, whether their economic contribution is unusually significant or whether they are at a 
stage at which they are supporting young children or elderly persons-or judgments about their stewardship of their own health. Horizontal equity, in the sense of "relevance", requires there to be equal treatment for those of equal merit, and vertical equity requires more favourable treatment of those with greater merit. Merit based on money strikes directly against several of the "relevancies" considered below and usually arises from a view of health care as a service no different in kind from any other to which monetary wealth gives access. The question is whether health care is one of the goods and services within the "rewards system" or not. (For a systematic account of two archetypical societies differentiated according to these "ideologies", see Culyer, Maynard and Williams. ${ }^{10}$ )

The overwhelming evidence is that the citizens of most countries have thoroughly rejected the "rewards" approach to health care. This approach has, however, a residual and continuing presence in the policy of some physicians of preferring males of working age to others (including females) when rationing access. This policy seems ad hoc, however and is not, so far as I know, enshrined in any statement of public policy.

The second version of the merit argument (number of dependents) is more frequent, and again there is patchy evidence that such a policy is adopted by physicians when defensible priorities are required. There is also survey evidence that people attach special significance to the health care needs of those with dependent children. ${ }^{11}$ This may, therefore, be a (vertical) principle of differentiation which a pluralist synthesis might incorporate into judgments of equity and policies to attain it.

The negative version of the merit argument dominates and conflicts with several of the other "relevancies". Its main role, and it is in this sense that it is most frequently heard, is to justify differential contributions by smokers. The most telling practical argument against it is that it is exceedingly difficult to think of any aspect of il health which is not influenced (albeit indirectly and only partially) by the lifestyle choices of individuals. Thus, if it were to be adopted as a relevant principle for equitable distribution, it would apply very widely, and there would be formidable problems in assessing the "contribution" of each individual's past negligence to current ill health and penalising each accordingly'.

\section{Need is relevant}

Medical care is a commonly cited example of a service that ought to be distributed according to "need". ${ }^{12-14}$ Let us suppose that what we mean when we say that something is needed is that it is needed for what it is able to accomplish. The thing asserted to be needed is instrumental-a necessary condition if a more ultimate objective is to be met. The view that "need" must be an instrumental concept has been strongly argued by Barry ${ }^{15}$ and Flew. ${ }^{16}$ It has been opposed by others (for example Miller, ${ }^{17}$ Thomson ${ }^{18}$ ) on the grounds that some statements using the word "need" are intrinsic and elliptical, or imply an objective which would be trivial to make explicit. For example, the statement: "surgeons need manual dexterity" is hardly elucidated by asking "why", for the answer might well be that "surgeons need manual dexterity in order to be surgeons". Similarly the statement: "Anthony needs open-heart surgery" is hardly elucidated by adding: "if he is to live".

The main reason for objecting to unsubstantiated assertions of need is that they assume, rather than inquire whether, the thing needed really is necessary. For example, modern technology may make an effective surgeon less dependent on manual dexterity. Therefore, if we are to stipulate the skills surgeons ought to have, it becomes important to be explicit in determining how surgeons should be trained. Or, if we're deciding on Anthony's treatment, we really do need to know whether open-heart surgery is appropriate for him, what the risks are, what the probability of success is, and what alternative actions might be taken. Moreover, these assertions assume that the objective really is the one sought. If the operation is likely to extend Anthony's life, will it do so only at the cost of a much lower quality of life? Or, how small must the probability of perioperative death be before Anthony or the doctor judges the risk worth taking? The assertion that this or that is "needed", even though its effectiveness may be disputed or unknown and even though the end sought may rank low in the priorities of those allocating resources, is a commonplace of medical politics. At the risk of redundancy then, there is much to be said for explicitness about the instrumentality of any resources asserted to be needed.

\section{Capacity to benefit}

The word "need" has a particular moral force, conveying the impression that needs ought to receive a higher priority than mere wants. This morally compelling aspect of "need" provides a further impetus for inquiry into the objectives served by whatever is asserted to be needed. The instrumental element of "need" is factual. It is true or false or disputable at a factual level, but even if the need is true, it doesn't follow that it ought to be met at public expense. Whatever is morally compelling about a need must come from the end served. Let us assume that there can be a need for health services only if there are grounds for believing that these services will enhance health, prevent its deterioration, or postpone death. These are the benefits sought from health care, and it follows that a need for health care can exist only when there is a capacity to benefit. ${ }^{12}{ }^{19}{ }^{20}$ It is rare, however, to have a fixed and unique technology of treatment. Thus, of the various possibilities available, the treatment needed is that judged to be the most appropriate in the particular circumstances of the case, which is that which is the most cost-effective. The amount needed is that sufficient to exhaust capacity to benefit. This definition captures the instrumental nature of need by defining it in terms of what is needed-resources. It also relates the need for 
resources to the moral objective sought-health for "flourishing"-which gives need its special moral status. It also defines a finite quantum of need (namely that which exhausts capacity to benefit) without building in distributional values about how much need ought to be met, a question still to be resolved.

As well as saying that health care is needed, one might say that health is needed, asserting another instrumentality, that health itself is needed to achieve some more ultimate state, such as the enjoyment of a "flourishing" life. It is possible to imagine some kind of regression whereby care is needed to have health, and health is needed to flourish, and flourishing is needed to have... . This regression is not, however, infinite. It stops when an ultimate objective is reached, an objective that is not needed for anything further. It might reasonably stop with "flourishing". The ultimate end is ethical in its own right, and this moral worth is transmitted back down the line to all the things which are necessary for its attainment. It is the end that imbues "need" with moral urgency and affords it priority over mere demands. It is also the crucial criterion in determining whether, and which, needs ought to be met.

\section{Culturally determined}

The use of the word "need" is often categorical or absolute and the need described ought therefore to be met categorically and absolutely. However, "health" is not categorical or absolute. It is a variable, for example, in functioning, activities of daily living, experience of pain, mobility and longevity and it is also largely culturally determined-both as regards the pathologies regarded as detrimental to a flourishing life in a particular community at a particular time and as regards the meaning of "flourishing". An extreme example of a clinical disease that was not regarded by some as "being ill" was pinto (dichromatic spirochetosis), a skin disease so prevalent among some South American tribes that the few single men not afflicted were regarded as pathological to the point of being excluded from marriage.

Another sort of extremism to which a categorical approach is prone, is illustrated by Harris ${ }^{21}$ : "Life saving has priority over life-enhancement and ... we should first allocate resources to those areas where they are immediately needed to save life and only when this is done should the remainder be allocated to alleviating non-fatal conditions." Harris's point is made without qualification. Thus the smallest possibility of the shortest extension to the most miserable of lives is to receive priority over the most sure and massive improvement in the quality of a life already expected to be long. Such is the absurd (even cruel) possibility inherent in a devotion to absolutism: a moral commitment held irrespective of its consequences and the harm those consequences inflict.

Despite these remarks, it is clear that the usage of the word "need" implies that the end served by the services held to be needed is particularly weighty.
Therefore, in discussing health policy, even if we draw back from absolutism, we ought nevertheless to restrict the word "need" to those instrumentalities effective in promoting the "important" attributes required for "flourishing".

\section{Five important implications of "need"}

The arguments just presented have five important and potentially radical implications.

First, need and ill health are not synonyms, and therefore one should not imagine that, in measuring the latter, one is also measuring the former. The only kind of health care that can be held to be needed is that which promotes health or reduces/ postpones deteriorations in health. This view contrasts sharply with a common view that identifies need with a current health or ill health state. For example, Daniels ${ }^{22}$ concludes with a definition of health in terms of an individual's impairment within what he calls the "normal opportunity range" for a person's life plans. But the weight of need then depends, not on the ability of health care to restore the range or compensate for its curtailment, but on the magnitude of the existing curtailment. By this definition, someone can need health care even though health care can make no contribution to the restoration or expansion of the range.

According to the definition advanced here, a need exists over the whole range of cost-effective health, wherever the marginal product (to use the economist's term) of care is positive in terms of health. Imagine, for example, that the capacity of a population to benefit from health care is ordered so that the person with the highest capacity to benefit is placed first in a parade, the person with the next highest capacity is placed second, and so on until individuals with zero capacity are reached. Only the individuals ahead of those with zero capacity are in need. Or, considering a single individual, imagine that by the application of one "unit" of health care, a given "pile" of health can be obtained and that we order incremental units in such a fashion that the biggest pile per unit is placed on the left, the next biggest immediately to its right, and so on until the piles have become tiny. Need exists only in the range where the piles are visible.

Second, capacity to benefit differs from need. On the one hand, capacity to benefit is defined in terms of outputs (improved health compared to what would have happened without the health care intervention). On the other hand, need is defined as the resources, valued in expenditure terms, required to exhaust capacity to benefit. It is possible, in a comparison of two individuals, for their capacities to benefit to differ but to be exhausted by the same expenditure on each. Hence the need for resources, as measured by expenditure, is the same, even though capacity to benefit is not. The two concepts are measured in different dimensions and do not necessarily coincide. Unfortunately, we know far too little about capacities to benefit and about costeffective packages of care. 
Third, need is forward- rather than backwardlooking. It is prospective rather than retrospective. It emphasises what can be done for people rather than what has previously happened to them or what their current situation is. Past and present are important only in so far as they may affect what can be done. Capacity to benefit is the difference between what a person's health is predicted to be over a period of time with and without care. It is not a before-andafter but a with-and-without comparison. Again, the inadequacy of a definition of need based only on current sickness, impairment or disability, is thrown into sharp relief. So, too, is the need for evidence about effectiveness.

There is evidence that not all health care is effective, let alone cost-effective, in the sense either that a patient's health is better with it than without it or that a given improvement is achieved with the least use of resources (see, for example Rachlis and Kushner. ${ }^{23}$ ) There are large variations in the rates of medical intervention, not only between different health care systems but also within them (for example McPherson, ${ }^{24} \mathrm{McPherson}$, Wennberg, Hovind and Clifford, ${ }^{25}$ Wennberg and Gittlesohn, ${ }^{26}$ and Sanders, Coulter, McPherson. ${ }^{27}$ ) These variations often reflect what has become known as a "surgical signature" in which the uncertainties, subjective judgments and preferences of particular physicians, vary. They are sometimes indicators of wasteful use of resources. Given the importance of need in considerations of equity, the elimination of ineffective practices is highly desirable. Such practices indicate that need is not being taken sufficiently seriously and that wasted resources could be redeployed, with no loss of patients' health, to redress inequities at the same level of expenditure. A better empirical basis for a macro assessment of the effectiveness of medical care is therefore essential.

Fourth, it will often be equitable for some needs to go unmet. This implication arises out of resource constraints. If resources are insufficient to exhaust all capacities to benefit and if it is deemed efficient, equitable, and otherwise desirable not to divert resources from other (non-health) uses, then the question arises as to what is the most equitable way of distributing existing resources across the range of needs. Some individuals may receive none and those who receive some may not receive all they need. Either can be compatible with equitable resource allocation.

\section{Incomplete equity principle}

Fifth, equal access is an incomplete equity principle. Access is probably best interpreted in terms of the costs, financial and other, to patients of using health care services. If equity requires that services go only to those who need them, then access (in the sense of "gaining admission" to the system in order for needs to be assessed) is plainly implied, so that needs can be assessed. Any impediments that discriminate between patients or that prevent such assessment will create inequity. Access, too, is instrumental. Equitable access is not an end in itself. Just as need is instrumental, in the sense of the resources necessary to eliminate capacity to benefit, access too, in the sense of "gaining admission", is instrumental so that needs can be assessed and then met equitably. However, access beyond the assessment stage is also important if needs are to be met. But whereas access for assessment requires equality for all who may have a capacity to benefit (one doesn't know until the case has been assessed), further access, which will depend upon the assessed needs, should be related to needs. How access should be related to needs depends, of course, on how needs are to be equitably met.

\section{Meeting needs equitably}

Is it true that (as Miller ${ }^{17}$ claims) "egalitarians are committed to the view that justice consists (minimally) in a distribution of resources according to need"? Or more generally, what kind of equality is right for a health care system which emphasises need? Miller's claim is equivalent to the needs version of horizontal and vertical equity-those in equal need ought to be treated equally and those in greater need ought to be treated in proportion to the greater need. It is quite easy to see that macro resource distribution in proportion to need conflicts with the foundations upon which the ethically compelling nature of need rests. Specifically, distribution according to need may worsen the distribution of health and, at best, will improve it only incidentally. Some imaginary cases will demonstrate this conflict.

In the first case, Anthony and Betty are judged to be equally sick and also to have an equal capacity to benefit. The resources available will permit either Anthony or Betty, but not both, to be restored to full health, and the same resource allocation for each is needed to accomplish this. An equal distribution of resources between the two will afford to each an equal increment in health. Since they started out with identical health states, the end state will also be identical. Here, then, is a case which is solidly egalitarian in that the individuals began equal, have equal capacities to benefit, have equal needs, are treated equally, and end up equal, though neither have their needs fully met. The road to equity is clearly signposted.

In the second case, Charlie and Dawn, too, start off with equal ill health. Suppose also that the amount of care (measured as expenditure) required to eliminate the capacity of each to benefit is the same-their need is equal-and, as before, that resources are insufficient for each to receive the maximum benefit of which he or she is capable. But suppose now, that, whereas Dawn can be restored to full health with the available technology and resources, Charlie's health can be only modestly improved. In this case, since need is the same, the horizontal equity principle requires expenditure to be divided equally between them. However, since Dawn's capacity to benefit is higher than Charlie's, she will receive a larger increment of health. Since the two started off with the same health, the result is that Dawn finishes up healthier than Charlie. Moreover, the reason for this is not that Charlie has exhausted his capacity to benefit, but that some 
resources which would benefit him are being devoted to the care of Dawn. Here the starting states of health were equal (which some may say is "need"), "need" in the sense advocated here was equal, but the outcome is a more unequal distribution of health.

There are several other possible conflicts between equity in terms of meeting needs and equity in terms of the final distribution of health. It is quite possible, in a starting situation of unequal health (unlike the case just discussed), to have a needs-based distribution of health care that actually exacerbates this initial inequality. ${ }^{28}{ }^{29}$ The important point is that there can be conflict between rules such as "distribution according to need", "distribution according to capacity to benefit", "distribution according to initial ill health", and "distribution designed to reduce inequalities in health". It is therefore necessary, except in special cases that cannot usually be expected, to choose between rival principles.

\section{Distribution of health}

Is there any reason to prefer any one of these principles over the others? Recall that the fundamental reason for caring about the distribution of health care is because of its effect on health, the ethical significance of which, hinges, in turn, on its role as a foundation for the flourishing of individuals in society. If this is indeed the reason for concern about the distribution of health care, then it is perverse to select need, capacity to benefit, or initial health as the characteristic in proportion to which health care should be allocated. None of these will necessarily result in the more equal distribution of health that is the true ethical imperative. They are not all equally faulty, although none is as egalitarian as it may initially have seemed. Distribution according to initial ill health is most likely to be egregiously inequitable, since it may waste substantial resources on those who will derive no benefit whatever while denying their application to the putting right of rectifiable inequalities. Distribution according to capacity to benefit will produce anomalies when the relatively healthy have higher capacities to benefit. Even distribution according to need is flawed. What ought to dominate is the distribution of health and how health care interventions can alter that for the better.

An equitable health care policy should seek to reduce the inequality in health (life expectation, selfreported morbidity, quality of life in terms of personal and social functioning) at every stage of the life-cycle. Such a policy must meet needs, but in proportion to the "distance' each individual is from the population average. Constraints may be desirable, some of which might be based on merit arguments. Moreover, it is probably not ethical to seek greater equality of health by reducing the health of the already relatively healthy. There may be compromises between the ethical desiderata of equity and efficiency in cases where egalitarian policies could reduce the variance of health only by causing total health to deteriorate. Such is pluralism. But the principle underlying the selection of needs to be met will not be a simple, proportionate one in terms of needs. Instead, needs will be met so as to reduce the dispersion of ill health in the community.

It also follows that judgments about some of the process-oriented conceptions of equity in health services, such as equity of opportunity to consume and equity of access, do not translate into equality of these processes, but have to be informed by judgments related to the contribution each can make to the ultimate objective of an equitable and, as far as possible, equal distribution of health. In judgments, for example, about the equity of introducing (further) user charges or about distributing health care facilities so that the time and transport costs of attending the facilities are reduced for patients, a decision has to be made as to whether such policies are conducive to meeting those needs that contribute most to reducing inequalities in health.

It is unlikely that precision is possible in such judgments, but the force of equity insists that these are the relevant considerations. The fact that there will never be sufficient information for the judgments to be reached with absolute confidence should not stand in the way of policies which push the system in the direction that equity demands. The perfect should not be allowed to become the enemy of the merely good.

Who should make these judgments about needs and the best ways of meeting them? Ultimately, it ought to be policy-makers accountable to the public, because the principles and priorities they select are quintessentially political matters of public policy (and they may be well advised to consult the public on key matters of value). But the concept of need has as one crucial ingredient the effectiveness of health care, and about this top-level policy makers may be expected to know little. Conversely, those who know a lot about effectiveness are ill-suited, through lack of accountability and training, to make the value judgments required in trading off the rival claims of articulate and powerful provider interests within the health care system. It is therefore clear that judgments about need and meeting needs at the macro level have to be made in a multidisciplinary fashion and, given their significance for public policy, in a publicly accountable way.

\section{From theory to policy}

In this section, I tease out what seem to be the practical implications for policy of the foregoing. The implications are organised into four groups: policy assumptions; target groups; information, and research.

\section{POLICY ASSUMPTIONS}

The first set of implications relates to the underlying "mind set" that the foregoing seem to require.

(a) There may be no single, overriding, equity principle to guide resource distributions. Policy-makers should be prepared to juggle with several, for example by including merit as well as equality of health. 
(b) In view of the possibility of multiple deprivation, policy-makers should watch for compensating inequities in non-health areas in terms of health care and vice versa.

(c) Need should be seen as a necessary condition for the receipt of equitably distributed public care.

(d) Equity requires, in the first instance, equal and universal access for assessment, especially in primary and emergency services; access for "approved" treatments ought to be unequal.

(e) "Approved" treatments are those that are needed and that make the most contribution to reducing inequalities in health.

(f) Slavish devotion to time-honoured principles of allocation in proportion to need and equal universal access should be avoided. They are misleading principles.

TARGET GROUPS

The next few implications relate to what I conjecture to be helpful ways of categorising patients and programmes.

(a) Since multiple deprivation is likely to prevail, there needs to be a powerful focus in policy-making and management structures so that a broad view of "basic goods" can be taken, their distributions monitored over time, and policies developed and likewise monitored. The simplest, though imperfect, way of doing this is to monitor the distribution of health, or ill health, and other significant "basics" by family, household, or by income, socioeconomic class, or known "risk factors" such as ethnicity, single parenthood, disability, and exposure to environmental hazards.

(b) Geographical distribution is usually an important dimension because regions, as well as individuals, can be multiply deprived and because there are usually significant variations in the ill health and in the avoidable or remediable ill health of regions.

(c) Medical specialties are important provider groups, some of which speak with voices more powerful than others. However, the potential of each to impact favourably on health is conjectural, while the significance of each for contributing to greater equality in health has hardly been investigated at all. Finding out more should be a priority.

(d) Such popular slogans as "prevention is better than cure" or "community care is better than institutional" ought to be tested in terms of the impact on the distribution of health that expansions or contractions might have, in addition to the prime requirement that each should have demonstrable effectiveness.

(e) Simply because of their vulnerability, those members of the community most at risk from changes in health care policy and those least likely to take advantage of the effective services available should be identified.
INFORMATION

Equity, like efficiency, demands particular forms of knowledge for its implementation. Moreover, the knowledge each demands is essentially the same. The main items are:

(a) Information on the current distribution of resources and health (or sickness) in relation to "target groups" above and any other groups perceived as ethically significant. Prior agreement on the meaning of "health" and "sickness" is necessary as is agreement on the appropriate statistical measures of inequality to be employed.

(b) Informed judgments about the effect of changes in resource distribution on the health of individuals and especially target groups.

(c) Information on the time and monetary costs faced by patients in accessing the system, and subsequently using this information to form judgments about the impact of user-charges, long travel times, and so on.

RESEARCH

The principal types of research needed are as follows:

(a) Data and information collection of the types enumerated above.

(b) Further research into concepts and theories of equity and efficiency directed at the policy and management needs of the ministry of health and other related divisions of government and the health services.

(c) More research into the non-health care determinants of health, which may have a greater (and more cost-effective) impact on health than health care.

(d) Further epidemiological and economic studies into effectiveness and cost-effectiveness, including the development and refinement of outcome measures of health for use at both macro and micro levels. A major priority ought to be research directed at the quantification of the potential health gains from alternative delivery strategies, changes in programmes defined by disease and changes in programmes defined by targeted groups. Research into "avoidable deaths" may provide a rough but workable set of clues as to where there are major, unexploited health improvements. An immediate task might be to commission a comprehensive and authoritative review of the existing epidemiological evidence on the relative cost-effectiveness of medical, including diagnostic, procedures.

(e) Research into the actual distributions of health and sickness: performed in advance of policy initiatives so that the initiatives be informed by the results; and routinely performed at an aggregate level for key groups, to monitor distributional changes over time and their likely determinants.

(f) Research into appropriate statistical measures of inequality and into practical survey/census procedures, with the empirical measures based 
on agreed concepts (health, equity, need, access, etc) and tested for content validity.

These policy proposals constitute a formidable agenda. The question is, of course, whether it is felt to be worthwhile welding the talent that usually exists in the developed world into a purposeful programme of interrelated and multidisciplinary activity-a programme in which policy and statistical branches of government, researchers, health care providers, health care users, carers and the public at large, are all interwoven and share a common purpose. Some Perestroika. Lots of Glasnost. And the goal?-the most efficient, humane, and equitable health care system yet devised by humankind!

\section{Acknowledgement}

This paper originated as a discussion paper for the Ontario Premier's Council. I am grateful (without implicating them in any way) for discussions with and comments from Martin Barkin, Peter Coyte, Amiram Gafni, Jonathan Lomas, Lesley McTurk, Gavin Mooney, Fraser Mustard, Owen O'Donnell, George Pink, Terry Sullivan, Adam Wagstaff and Alan Williams. I am also grateful for the hospitality of Peggy Leatt.

Anthony $\mathcal{F}$ Culyer is Professor of Economics, Department of Economics Eo related Subjects, University of York, Heslington, York.

\section{References \\ 1 Veatch RM. Ethical dimensions of the distribution of health care. In: Van der Gaag J, Neenan WB, Tsukuhara, T eds. Eco- nomics of health care. New York: Praeger, 1982: 3-24. \\ 2 Brody B. Life and death decision making. New York: Oxford Uni- versity Press, 1988 \\ 3 Tobin J. On limiting the domain of inequality. Fournal of Law and Economics 1970;5:263-78. \\ 4 Mill JS. On liberty. In: Warnock M, ed. Utilitarianism. London: Collins, 1962: 260 . \\ 5 Sen AK. Personal utilities and public judgments: or what's wrong with welfare economics. Economic fournal 1979;589: wrong \\ 6 Sen AK. Equality of what? The Tanner lectures on human values. Cambridge: Cambridge University Press, 1980.}

7 Sen AK. Commodities and capabilities. Amsterdam: NorthHolland, 1986.

8 Stanley J. The Appleton Consensus Conference: suggested international guidelines for decisions to forego medical treatment. Fournal of Medical Ethics 1989;15:129-36.

9 Mooney GH. Equity in health care: confronting the confusion. Effective Health Care 1983;1:179-85.

10 Culyer AJ, Maynard AK, Williams AH. Alternative systems of health care provision: an essay on motes and beams. In: Olson $\mathrm{M}$, ed. A new approach to the economics of health care. Washington DC: American Enterprise Institute, 1982: 131-50.

11 Williams AH. Economics and the rational use of medical technology. In Rutten FHH, Reiser SJ, eds. The economics of medical technology. Berlin: Springer, 1988.

12 Culyer AJ. Need and the National Health Service. London: Martin Robertson, 1976.

13 Gillon R. Philosophical medical ethics. New York: Wiley, 1985.

14 Braybrooke D. Meeting needs. Princeton: Princeton University Press, 1987.

15 Barry B. Political argument. London: Routledge and Kegan Paul, 1965.

16 Flew A. Wants or needs, choices or commands? In: Fitzgerald $\mathrm{R}$, ed. Human needs and politics. London: Pergamon Press, 1977: 213-28.

17 Miller D. Social justice. Oxford: Clarendon Press, 1976

18 Thomson G. Needs. London: Routledge and Kegan Paul, 1987.

19 Williams AH. Need as a demand concept (with special reference to health). In Culyer AJ, ed. Economic problems and social goals. London: Martin Robertson, 1974: 60-76.

20 Williams AH. Need-an economic exegesis. In: Culyer AJ, Wright KG, eds. Economic aspects of health services. London: Martin Robertson, 1978: 32-45.

21 Harris J. QALYfying the value of life. Fournal of Medical Ethics 1987;13:117-23: at 120 .

22 Daniels N. Fust health care. Cambridge: Cambridge University Press, 1985: 35

23 Rachlis M, Kushner C. Second opinion: what's wrong with Canada's health care system and how to fix it. Toronto: Harper and Collins, 1989.

24 McPherson K. Variations in hospitalization rates: why and how to study them. London: King's Fund Institute, 1988.

25 McPherson K, Wennberg J, Hovind O, Clifford, P. Small area variation in the use of common surgical procedures: an variation in the use of common surgical procedures: an Norway. New England Fournal of Medicine 1982;307:1310-14.

26 Wennberg J, Gittlesohn, A. Variations in medical care among small areas. Scientific American 1982;246:100-11

27 Sanders D, Coulter A, McPherson K. Variations in hospital admission rates: a review of the literature. London: King's Fund, 1989.

28 Culyer AJ. Conflicts between equity concepts and efficiency in health: a diagrammatic approach. In: El-Agraa A, ed. Public and international economics. Basingstoke: Macmillan, 1993: 42-58.

29 Culyer AJ, Wagstaff A. Equity and equality in health and health care. Fournal of Health Economics 1993;12:431-57.

\section{News and notes \\ Annual Intensive One-week Course in Medical Ethics}

The next Annual Intensive One-week Course in Medical Ethics will be held at Imperial College, London from September $17-21$.

For further information please contact: Centre for Continuing Education: email: cpd@ic.ac.uk 